\title{
CHANGES IN THE STRUCTURE OF URBAN MOBILITY WITH THE DEVELOPMENT OF PUBLIC TRANSPORT
}

\author{
ALEXEY FADYUSHIN \\ Department of Road Transport Operation, Industrial University of Tyumen, Russia
}

\begin{abstract}
The Ministry of Transport of the Russian Federation has announced the possibility of introducing free fare public transport in cities by 2035 and charging car owners for using highways. The experience of other European cities shows that with introduction of free fare public transport, the share of public transport trips increases insignificantly, while the number of trips by individual transport, bicycle and on foot decreases. The paper examines the impact of public transport fare on the transport demand structure. The structure of transport demand is determined using simulation modeling on a transport macro-model of a large city with population of 800,000 people that does not have off-street transport. The paper proposes a criterion for determining generalized costs of travel by different transport systems, which converts monetary costs into time fares. Using the proposed criterion, it is possible to determine the cost of travel by different transport systems (individual transport, taxi, CarSharing, public transport, cycling and walking).
\end{abstract}

Keywords: public transport, transport demand, free fare public transport, transport planning, transport modelling.

\section{INTRODUCTION}

It is impossible to imagine a modern city without sustainable mobility of population. To ensure sustainable urban mobility, priority conditions are created for public transport and cyclists, compared to personal car users [1], [2]. Development of public transport and covering travel needs by public transport ensures social justice for citizens [3], [4].

The paper [5] shows that it is necessary to consider various factors (place of residence and distance from the center, income, age, social status, and route network characteristics) when making a decision on compensation for part of the costs of public transport trips. Differentiation of compensation for public transport trips, with the total and specific costs of a person taken into account, allows to increase the accessibility of public transport and achieve greater social justice.

In the course of analyzing the results of the work [6], the authors call for considering the issue of targeted tariff subsidies for low-income groups in the system. From a political point of view, it is necessary to recognize the potential social value of public transit investments, such as BRT, in the context of their integration with the city structure, and of considering socially differentiated needs.

The authors of the study [7], [8] show that with introduction of free fare public transport, the total number of public transport trips increases due to the fact that public transport users take more trips and reduce the number of pedestrian movements and bicycle rides. The share of public transport users with introduction of free fare increased insignificantly, thus the goals of achieving sustainable mobility in cities with free fare public transport were not achieved. The authors of the article consider the issue of additional costs for the city budget when introducing free fare public transport and the necessity to reallocate funds for public transport from other items. Free fare public transport introduction creates travel entitlements for the category of people with high income who do not actually need such compensation for expenses. The effect of free fare public transport will be the absence of ticket sales costs. It is noted that free fare public transport is easier and more effective to implement in small and 
medium-sized cities. In large cities, it is more difficult to achieve sustainable mobility by means of free transport. This event should be thoroughly calculated and modeled, since it might be complicated to cancel such a decision afterwards. At present, there is no scientific evidence to suggest that free fare public transport can have a significant impact on sustainable mobility.

The results of a survey of residents of the cities in work [9] show that the most important factors when choosing public transport are well developed route network and regularity. The travel fare is indicated as the most important factor by $9.8 \%$ of respondents. This suggests that for residents of megalopolises, the quality of public transport is more important than travel fare.

Other important factors for choosing public transport are difficulties in finding a free parking space, parking fees and road congestion. The main reasons why residents travel by car are greater comfort, shorter travel time by car, and transportation of goods or purchases. This means that the concept of free fare public transport does not meet the most important expectations regarding public transport. This study concludes that introduction of free fare public transport is not enough for transition from a private car to public transport.

The paper [10] describes the interrelation between public transport fare and availability and the area of residence location in the city.

An important influence on the share of public transport trips is the price and number of paid parking spaces in the central part of the city, as well as the level of infrastructure development for public transport, cyclists and pedestrians [11].

Introduction of free fare public transport in cities and reduction in the number of private transport users allows the following [12]-[14]:

- ensuring mobility of population, especially of the lower-wealth groups of population,

- reducing traffic congestion,

- reducing the necessity of building new expensive interchanges, and

- ensuring environmental sustainability of the city.

In 2013, the city of Tallinn introduced free fare public transport. Based on the results of annual municipal surveys, the average number of trips per person in one year has not undergone significant changes, while the structure of transport demand has changed:

- the number of public transport trips increased from $55 \%$ to $63 \%$,

- the number of individual transport trips decreased from $31 \%$ to $28 \%$, and

- cycling and walking movements decreased from $14 \%$ to $9 \%$.

Experts note that due to the increase in the city population, the absolute number of cars and users of individual transport has increased, and the transition to public transport has developed as an undesirable transition from walking [15], [16].

In 2020, The Ministry of Transport of Russia announced the possibility of introduction of free fare public transport in cities by 2035. The Ministry of Transport proposes to introduce free fare public transport upon condition that toll roads for car owners will be introduced. This scheme implies that from 2025, tolls will be collected on regional roads, and by 2035 they will be collected on all roads, including the road network of urban agglomerations.

The purpose of the work is to establish the dependence of changes in the transport demand structure on public transport fare. 


\section{MATERIALS AND METHODS}

To assess changes in the structure of transport demand, transport modeling was carried out in PTV Visum 18 program. The macroscopic transport model of the city includes 400 transport districts, 7,750 junctions, and 17,300 sections. The total length of the city's road network is $2,424 \mathrm{~km}$, including $1,200 \mathrm{~km}$ of highways and 381 traffic lights. As a result of the transport model calibration, the correlation coefficient of the calculated and measured values of traffic intensity exceeded 0.85 .

PTV Visum program includes a 4-stage standard model of transport demand, which consists of generating transport traffic, distributing it by correspondence, choice of a transport, and assignment it on the road network. In the choice of a transport procedure, based on the criterion "Utility of a trip by the i-th type of transport," the probability of a trip by the i-th type of transport is determined according to the Logit distribution model. Usually, the greater the utility of a trip by the i-th type of transport, the greater the probability of a trip by the i-th type of transport.

In the model of Tyumen, the probability of a trip by the $\mathrm{i}$-th type of transport is determined based on the time spent on the i-th type of transport. As noted by the program developers in PTV Visum user guide, utility is the inverse function to resistance and travel costs [17].

Yakimov notes in his monograph [18] that resistance is travel cost calculated in rubles, minutes, or another unit of measurement. Resistance is the sum of time cost (cost of a minute multiplied by travel time) and operating costs (cost of $1 \mathrm{~km}$ of vehicle mileage multiplied by travel length).

In this paper, resistance is calculated as the sum of travel time and travel cost converted into time using a special coefficient presented in the eqn (1):

$$
R_{i}=T_{i}+k \cdot F_{i}
$$

where $R_{i}$ - resistance for the i-th transport system, min.; $T_{i}$ - travel time, min.; $k$ - coefficient for converting money into time, min./rub.; $F_{i}-$ travel cost, rub.

The coefficient for converting money into time is calculated based on the average salary for a standard 40-h work week. As a result, this money - time ratio for the city of Tyumen in 2021 is $0.2 \mathrm{~min}$ per ruble or $12 \mathrm{~s}$ per ruble. When calculated using the method of Yakimov, the coefficient for converting money into time for the city of Tyumen in 2021 was 5 rubles per minute.

Travel cost for different types of transport is calculated based on tariffs. For example, the cost of a taxi ride is calculated based on the Economy tariff in Yandex.Taxi [19]. For CarSharing, based on the tariff in Cars 7 service, the cost of a travel by private transport is determined using the calculator of the analytical agency Autostat [20] that estimates the cost of owning a car. Travel cost for different types of transport is calculated using the eqns (2)(5):

$$
\begin{gathered}
F_{\text {taxi }}=80+6 \cdot(L-2), \\
F_{c s}=T \cdot 7.9, \\
F_{c a r}=L \cdot 7.5, \\
F_{b u s}=n \cdot 27,
\end{gathered}
$$


where $F_{i}$ - travel cost for the i-th transport system, rub.; $T_{i}$ - travel time, min.; $L_{i}-$ travel length, $\mathrm{km} ; n$ - rides number by a transport type.

Table 1 shows an example of resistance calculation for a trip from the central part of Tyumen to a peripheral area. The lower row of the table shows the calculated resistance value. The maximum resistance value for this correspondence is for pedestrians, and the minimum value is for cyclists and public transport users. The average resistance value is for taxi.

Table 1: Resistance for various types of transport.

\begin{tabular}{|l|c|c|c|c|c|c|}
\hline \multirow{2}{*}{ Expenses } & \multicolumn{7}{c|}{ Vehicle type } \\
\cline { 2 - 8 } & Bike & Ped & Car & Taxi & CarSharing & Bus \\
\hline Travel length, km & 11 & 10 & \multicolumn{3}{c|}{13} & 10 \\
\hline In-vehicle travel time, min. & 54 & 121 & \multicolumn{3}{c|}{28} & 30 \\
\hline Approach time on foot, min. & & & & & 2 & 8 \\
\hline Vehicle waiting time (or rental), min. & & & & 6 & 2 & 5 \\
\hline Vehicle return time, min. & & & & & 2 & \\
\hline Egress time, min. & & & & & & 5 \\
\hline Walk time to transfer, min. & & & & & & 0 \\
\hline Waiting time for the 2nd vehicle, min. & & & & & & 0 \\
\hline Total travel time, min. & 54 & 121 & 28 & 34 & 34 & 48 \\
\hline Tariff, rub./km (rub./min. - for CarSharing) & & & 7.5 & 6 & 7.9 & 27 \\
\hline Price of paid parking, rub./hour & & & 40 & & & \\
\hline Paid parking time, hours & & & 4 & & & \\
\hline Total travel cost, rub. & 0 & 0 & 258 & 146 & 269 & 27 \\
\hline Resistance, min. & 54 & 121 & 80 & 63 & 88 & 53 \\
\hline
\end{tabular}

3 RESULTS

Fig. 1 shows the results obtained by means of modeling.

With introduction of free fare public transport, the share of public transport trips in Tyumen increases, while the share of trips by other types of transport decreases. Traffic parameters are also defined, for example, when the cost of public transport trips increases, travel time by individual transport increases and the average speed decreases. These changes are directly related to the increase in the number of individual transport users and intensity of individual transport traffic in the city. At the same time, the changes in traffic parameters are quite insignificant, for example, when changing from 0 to 54 rubles, the average travel time increased by $1 \mathrm{~min}$ or $4 \%$, and the average speed decreased from 26 to $25 \mathrm{~km} / \mathrm{h}$, which is $4 \%$. However, these models with free fare public transport do not show the costs for individual transport on toll roads, according to the mechanism of the Ministry of Transport planned for 2035 .

\section{CONCLUSION}

With introduction of free fare public transport, an additional 2.5-3 billion rubles (28-33 million euros) per year will be required from the city budget. 


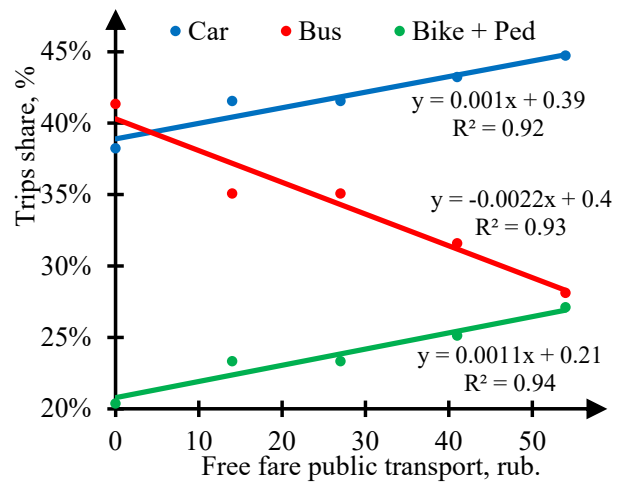

(a)

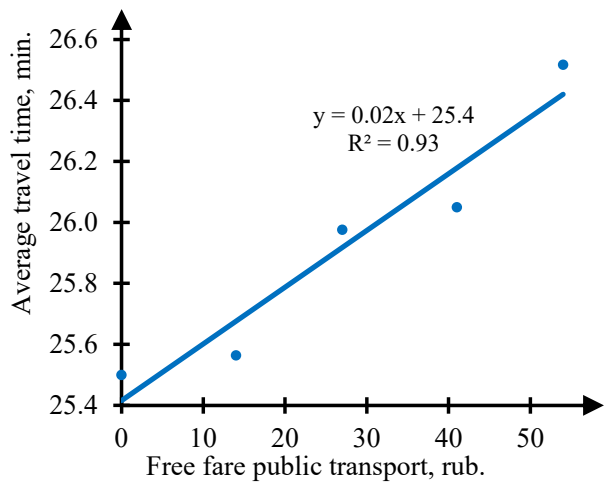

(b)

Figure 1: The impact of public transport fare on (a) the structure of transport demand; and (b) the average travel time by individual transport.

Recently, public transport has received more attention from the authorities of Russian cities. To attract users to public transport, rolling stock is being renewed, route network is being developed, and the average speed of traffic is being increased through priority-based activities. However, it is advisable to implement such measures in conjunction with measures that restrict travel by individual transport.

Future work plans are the following.

- Modeling introduction of paid parking space in the business part of the city (central part of Tyumen).

- Considering various segments of society (students, pensioners, etc.) in the model and assessing the impact of public transport fare with different fare systems on the change in the transport demand structure of population.

- Modeling capacity of vehicles and assessing the impact of transition to large and extralarge capacity buses on the transport demand structure of population.

- Modeling sharing systems (CarSharing, BikeSharing), taxi, RideSharing and Park\&Ride systems and assessing the impact of ride fares on changes in the transport demand structure.

- Modeling and evaluating the impact of discomfort of public transport travel and cycling on changes in the transport demand structure of population.

- Conducting a survey of the population of Russia on transport mobility and choice of a transport type.

- Correlation and regression analysis of simulation and survey results.

\section{ACKNOWLEDGEMENTS}

The research was prepared as a part of implementation of a state assignment in the field of science for scientific projects carried out by teams of researchers in scientific laboratories of Industrial University of Tyumen subordinate on the project: New patterns and solutions for the functioning of urban transport systems in the paradigm "Transition from owning a personal car to mobility as a service." 


\section{REFERENCES}

[1] Delle Site, P. \& Filippi, F., Effectiveness of public transport periodization. WIT Transactions on the Built Environment, vol. 18, WIT Press: Southampton and Boston, pp. 395-402, 1995. DOI: 10.2495/UT950451.

[2] Schoeman, C.B., International perspectives on transportation and urban form integration. International Journal of Transport Development and Integration, 1(1), pp. 49-60, 2017. DOI: 10.2495/TDI-V1-N1-1-15.

[3] Cuthill, N., Cao, M., Liu, Y., Gao, X. \& Zhang, Y., The association between urban public transport infrastructure and social equity and spatial accessibility within the urban environment: An investigation of Tramlink in London. Sustainability (Switzerland), 11(5), p. 1229, 2019. DOI: 10.3390/su11051229.

[4] Oviedo, D., Scholl, L., Innao, M. \& Pedraza, L., Do bus rapid transit systems improve accessibility to job opportunities for the poor? The case of Lima, Peru. Sustainability (Switzerland), 11(10), p. 2795, 2019. DOI: 10.3390/su11102795.

[5] Börjesson, M., Eliasson, J. \& Rubensson, I., Distributional effects of public transport subsidies. Journal of Transport Geography, 84, p. 102674, 2020.

DOI: $10.1016 /$ j.jtrangeo.2020.102674.

[6] Oviedo, D., Scholl, L., Innao, M. \& Pedraza, L., Do bus rapid transit systems improve accessibility to job opportunities for the poor? The case of Lima, Peru. Sustainability (Switzerland), 11(10), p. 2795, 2019. DOI: 10.3390/su11102795.

[7] Tomanek, R., Free-fare public transport in the concept of sustainable urban mobility. Transport Problems, 12, pp. 95-105, 2017. DOI: 10.20858/tp.2017.12.se.8.

[8] Štraub, D. \& Jaroš, V., Free fare policy as a tool for sustainable development of public transport services. Human Geographies, 13(1), pp. 45-59, 2019.

DOI: 10.5719/hgeo.2019.131.3.

[9] Grzelec, K. \& Jagiełło, A., The effects of the selective enlargement of fare-free fare public transport. Sustainability (Switzerland), 12(16), p. 6390, 2020.

DOI: $10.3390 /$ SU12166390.

[10] Dewita, Y., Burke, M. \& Yen, B.T.H., The relationship between transport, housing and urban form: Affordability of transport and housing in Indonesia. Case Studies on Transport Policy, 8(1), pp. 252-262, 2020. DOI: 10.1016/j.cstp.2019.01.004.

[11] Zakharov, D. \& Fadyushin, A., Changes in the structure of urban mobility with the development of infrastructure for public transport and cyclists in cities. WIT Transactions on the Built Environment, vol. 200, WIT Press: Southampton and Boston, pp. 49-60, 2020. DOI: 10.2495/UT200051.

[12] Hodge, D.C., Orrell, J.D. \& Strauss, T.R., Fare-free Policy: Costs, Impacts on Transit Service, and Attainment of Transit System Goals, Washington State Transportation Centre, 1994.

[13] Storchmann, K., Externalities by automobiles and fare-free transit in Germany: A paradigm shift? Journal of Public Transportation, 6(4), pp. 89-105, 2003.

[14] Rye, T. \& Mykura, W., Concessionary bus fare for older people in Scotland - are they achieving their objectives? Journal of Transport Geography, 17, pp. 451-456, 2009.

[15] Cats, O., Susilo, Y.O. \& Reimal, T., The prospects of fare-free fare public transport: Evidence from Tallinn. Transportation, 44, pp. 1083-1104, 2017.

[16] Cats, O., Reimal, T. \& Susilo, Y., Evaluating the impacts of fare-free fare public transport policy: The case of Tallinn, Estonia. Transportation Research Record, 2415, pp. 89-96, 2014.

[17] PTV AG, PTV Visum manual. http://cgi.ptvgroup.com/vision-help/VISUM_18_ ENG/. Accessed on: 11 May 2021. 
[18] Yakimov, M.R., Transport Planning: Creating Transport Models of Cities: Monograph/M.R. Yakimov, Logos: Moscow, 188p, 2013.

[19] Yandex.Taxi, Taxi price. https://taxi.yandex.ru/ru_ru/tumen/tariff/. Accessed on: 11 May 2021.

[20] Price.Auto, Estimating the cost of car ownership. https://cena-auto.ru/calculator/tco/. Accessed on: 11 May 2021. 